\title{
Pegylated Liposomal Doxorubicin/Trastuzumab Regimen
}

National Cancer Institute

\section{Source}

National Cancer Institute. Pegylated Liposomal Doxorubicin/Trastuzumab Regimen. NCI Thesaurus. Code C11744.

A regimen consisting of pegylated liposomal doxorubicin and trastuzumab that may be used in the treatment of human epidermal growth factor receptor 2 (HER2)-positive metastatic breast cancer. 